comments- have indicated that the ipods provide a positive experience for patients and families with a wide range of musical tastes.

Staff comments were collected through an online survey.

Raising staff awareness of the benefits to patients of listening to music of their own individual choice rather than that selected by nursing staff from a central CD player, radio, piano or organ has prompted another auxiliary nurse to survey Day Therapy patients and find out what their music preferences are.

This poster describes the background to this service, comments from patients and families, and the results of the two surveys.

\title{
P98 MUSIC TO SOOTHE THE SOUL
}

Kate Edmondson, Dawn Garlick, Vicki Wright Queenscourt Hospice, Southport, England

10.1136/bmjspcare-2011-000105.98

Background A talented composer and musician when admitted to a hospice many miles from home, missed the spiritual comfort provided by his own music collection stored on his ipod. Hospice CD 's were not to his taste! When he died his partner was distressed and guilt ridden because she had not been able to access his music for him. She decided to raise money to provide ipods for all inpatients to use and enjoy.

Aims To provide each inpatient with an extra source of comfort and relaxation to suit their own individual taste.

Method Enough money was raised to buy 14 ipods and docking stations, 12 month supply of disposable headphones and a laptop for downloading the music.

An eclectic range of music of all genres was downloaded, including music composed and recorded by the patient and partner.

One auxiliary nurse volunteered to take responsibility for downloading music that had special meaning for individual patients as requested.

Results Comments from patients and families that have used the ipods are collected, also the types of music requested, 